\title{
Activated protein $C$ ameliorates impaired renal microvascular oxygenation and sodium reabsorption in endotoxemic rats
}

\author{
Emre Almac ${ }^{1,2 \dagger}$, Tanja Johannes ${ }^{1,3 \dagger}$, Rick Bezemer ${ }^{1 *}$, Egbert G Mik ${ }^{3}$, Klaus E Unertl ${ }^{4}$, AB Johan Groeneveld ${ }^{5}$
} and Can Ince ${ }^{1,5}$

* Correspondence:

r.bezemer@amc.uva.nl

†Equal contributors

${ }^{1}$ Department of Translational

Physiology, Academic Medical Center, University of Amsterdam, Meibergdreef 9, 1105 AZ Amsterdam, The Netherlands Full list of author information is available at the end of the article

\begin{abstract}
Introduction: We aimed to test whether continuous recombinant human activated protein C (APC) administration would be able to protect renal oxygenation and function during endotoxemia in order to provide more insight into the role of coagulation and inflammation in the development of septic acute kidney injury.
\end{abstract}

Methods: In anesthetized, mechanically ventilated Wistar rats, endotoxemia was induced by lipopolysaccharide administration (10 mg/kg i.v. over $30 \mathrm{~min}$ ). One hour later, the rats received fluid resuscitation with 0 (LPS + FR group; $n=8), 10$ (APC10 group; $n=8$ ), or 100 (APC100 group; $n=8$ ) $\mu \mathrm{g} / \mathrm{kg} / \mathrm{h} \mathrm{APC} \mathrm{for} 2 \mathrm{~h}$. Renal microvascular oxygenation in the cortex and medulla were measured using phosphorimetry, and renal creatinine clearance rate and sodium reabsorption were measured as indicators of renal function. Statistical significance of differences between groups was tested using two-way ANOVA with Bonferroni post hoc tests.

Results: APC did not have notable effects on systemic and renal hemodynamic and oxygenation variables or creatinine clearance. The changes in renal microvascular oxygenation in both the cortex $(r=0.66 ; p<0.001)$ and medulla $(r=0.80 ; p<0.001)$ were correlated to renal sodium reabsorption.

Conclusion: Renal sodium reabsorption is closely correlated to renal microvascular oxygenation during endotoxemia. In this study, fluid resuscitation and APC supplementation were not significantly effective in protecting renal microvascular oxygenation and renal function. The specific mechanisms responsible for these effects of APC warrant further study.

Keywords: Endotoxemia; APC; Activated protein C; AKI; Microcirculation

\section{照 Springer}

\section{Introduction}

The prevalence of acute kidney injury (AKI) in septic patients is high, approximately $20 \%$ to $50 \%$, and the AKI-related mortality rate is $75 \%$ in septic shock compared to $45 \%$ without sepsis $[1,2]$. The pathogenesis and pathophysiology of sepsis-induced AKI is highly complex, and current treatment strategies are mainly supportive rather than curative [3]. There is a growing body of evidence that microcirculatory dysfunction accompanied by tissue dysoxia might play a key role in the development of septic organ damage [4,5]. Excessive release of pro-inflammatory mediators and disturbances

(c) 2013 Almac et al.; licensee Springer. This is an Open Access article distributed under the terms of the Creative Commons

Attribution License (http://creativecommons.org/licenses/by/2.0), which permits unrestricted use, distribution, and reproduction in any medium, provided the original work is properly cited. 
in the coagulation system are believed to be involved in the pathogenesis of sepsis; both leading to microcirculatory dysfunction and consequent organ failure [6,7].

Activated protein $\mathrm{C}$ (APC) is an important endogenous protein that modulates coagulation and inflammation by promoting fibrinolysis and inhibiting thrombosis and inflammation [8-10]. Different experimental and clinical studies could demonstrate that the administration of APC improved outcome of severe sepsis [11-15]. With respect to the protective effects of APC on the kidney during sepsis, especially the group of Gupta et al. has identified specific mechanisms of action of APC in rat models of experimentally induced septic AKI [16-19]. Another group, furthermore, showed that APC reduced ischemia/reperfusion $(I / R)$-induced renal injury in rats [20].

Besides its potentially beneficial effects, there are serious concerns regarding the safety and efficacy of APC treatment in critically ill septic patients [21]. These concerns led to discontinuation of all ongoing clinical trials using APC for treatment of severe sepsis. APC is no longer suggested for the treatment of severe sepsis or septic shock. Despite these developments, investigating the effects of APC in experimental studies may provide more insights into the development of septic AKI.

The above mentioned studies have provided key insights into the beneficial effects of APC in sepsis; however, none of these studies have investigated the effects of APC on renal oxygenation and function in terms of tubular sodium reabsorption. In the present study, we tested whether continuous recombinant human APC administration would be able to protect renal oxygenation and function during the acute phase of endotoxemia and fluid resuscitation.

\section{Materials and methods}

All experiments in this study were approved by the institutional Animal Experimentation Committee of the Academic Medical Center of the University of Amsterdam (institutional protocol number: DFL 100404). Care and handling of the animals were in accordance with the guidelines for Institutional and Animal Care and Use Committees. The experiments were performed on 32 Wistar male rats (Harlan Laboratories, Inc., Boxmeer, The Netherlands) with mean \pm SD body weight of $318 \pm 15 \mathrm{~g}$.

\section{Surgical preparation}

The rats were anesthetized with an intraperitoneal injection of a mixture of $100 \mathrm{mg} / \mathrm{kg}$ ketamine (Nimatek', Eurovet, Bladel, The Netherlands), $0.5 \mathrm{mg} / \mathrm{kg}$ medetomidine (Domitor, Pfizer Inc., New York, NY, USA), and $0.05 \mathrm{mg} / \mathrm{kg}$ atropine sulfate (Centrafarm Pharmaceuticals B.V., Etten-Leur, The Netherlands). After tracheotomy, the animals were mechanically ventilated with a $\mathrm{FiO}_{2}$ of 0.4 . Body temperature was maintained at $37^{\circ} \mathrm{C} \pm 0.5^{\circ} \mathrm{C}$ during the entire experiment by external warming. The ventilator settings were adjusted to maintain end-tidal $\mathrm{PCO}_{2}$ between 30 and $35 \mathrm{mmHg}$, and arterial $\mathrm{PCO}_{2}$ between 35 and $40 \mathrm{mmHg}$.

The vessels were cannulated with polyethylene catheters (outer diameter $=0.9 \mathrm{~mm}$; B. Braun Melsungen AG, Melsungen, Germany) for drug and fluid administration and hemodynamic monitoring. A catheter in the right carotid artery was connected to a pressure transducer to monitor the mean arterial blood pressure (MAP) and heart rate. The right femoral artery was cannulated for blood sampling. The right femoral vein 
was cannulated for continuous infusion of Ringer's lactate $(15 \mathrm{~mL} / \mathrm{kg} / \mathrm{h}$; Baxter B.V., Utrecht, The Netherlands) and ketamine (50 mg/kg/h; Nimatek ${ }^{\circ}$; Eurovet).

The left kidney was exposed, decapsulated, and immobilized in a Lucite kidney cup (K. Effenberger, Pfaffingen, Germany) via a 4-cm incision in the left flank. The renal vessels were carefully separated under preservation of nerves and adrenal gland. A perivascular ultrasonic transient time flow probe was placed around the left renal artery (type 0.7 RB; Transonic Systems Inc., Ithaca, NY, USA) and connected to a flow meter (T206; Transonic Systems Inc.) to continuously measure the renal blood flow (RBF). An estimation of the renal vascular resistance (RVR) was made as RVR $\left(\right.$ dynes s $\mathrm{cm}^{-5}$ ) = (MAP / RBF). The left ureter was isolated, ligated, and cannulated with a polyethylene catheter for urine collection.

After the surgical protocol (approximately $60 \mathrm{~min}$ ), one optical fiber was placed 1 $\mathrm{mm}$ above the decapsulated kidney and another optical fiber $1 \mathrm{~mm}$ above the renal vein to measure oxygenation in the renal microvasculature and renal vein, respectively, using phosphorimetry [22-24]. A small piece of aluminum foil was placed on the dorsal site of the renal vein to prevent contribution of underlying tissue to the phosphorescence signal in the venous oxygenation measurement. Oxyphor G2 (a two-layer glutamate dendrimer of tetra-(4-carboxy-phenyl) benzoporphyrin; Oxygen Enterprises Ltd., Philadelphia, PA, USA) was subsequently infused $(6 \mathrm{mg} / \mathrm{kg}$ IV over $5 \mathrm{~min}$ ) followed by a 30 -min stabilization period. A short description of phosphorimetry is given below, and a more detailed description of the technology has been provided elsewhere [22,23].

\section{Experimental protocol}

After baseline measurements were performed 30 min after Oxyphor G2 infusion, endotoxemic shock was induced in three groups of rats ( $n=8 /$ group) by a bolus of lipopolysaccharide (LPS, $10 \mathrm{mg} / \mathrm{kg}$, serotype 0127:B8, Sigma-Aldrich, Zwijndrecht, The Netherlands). One hour after the LPS bolus, fluid resuscitation $(5 \mathrm{~mL} / \mathrm{kg}$ followed by 5 $\mathrm{mL} / \mathrm{kg} / \mathrm{h}$; Voluven ${ }^{\circ}, 6 \%$ HES 130/0.4; Fresenius Kabi, Schelle, Belgium) was started and continued for $2 \mathrm{~h}$. In addition to the fluid resuscitation, one group received $10 \mu \mathrm{g} / \mathrm{kg} / \mathrm{h}$ APC and one group received $100 \mu \mathrm{g} / \mathrm{kg} / \mathrm{h} \mathrm{APC} \mathrm{(recombinant} \mathrm{human} \mathrm{activated} \mathrm{protein} \mathrm{C;}$ Drotrecogin Alpha, Xigris ${ }^{\circ}$, Eli Lilly and Company, Indianapolis, IN, USA). A fourth group of rats $(n=8)$ did not receive LPS or fluid resuscitation and served as a sham-operated time control group. All the rats, except for those in the time control group, received the same fluid volume. The experiments were terminated by infusion of $1 \mathrm{~mL}$ of $3 \mathrm{M}$ potassium chloride $(\mathrm{KCl})$, after which the kidneys were removed and weighted.

\section{Blood variables}

Arterial blood samples $(0.5 \mathrm{~mL})$ were taken from the femoral artery at the following time points: (1) baseline; (2) $1 \mathrm{~h}$ after the LPS bolus, before the start of fluid resuscitation; and (3) after $2 \mathrm{~h}$ of fluid resuscitation. The blood samples were replaced by the same volume of Voluven. The samples were analyzed for blood gas values (ABL505 blood gas analyzer; Radiometer Medical ApS, Copenhagen, Denmark), hemoglobin concentration, and hemoglobin oxygen saturation (OSM3; Radiometer Medical ApS). Additionally, plasma creatinine concentrations were determined in all the samples. 


\section{Renal microvascular and venous oxygenation}

Microvascular oxygen tension in the renal cortex $\left(\mathrm{C} \mu \mathrm{PO}_{2}\right)$, outer medulla $\left(\mathrm{M} \mu \mathrm{PO}_{2}\right)$, and renal venous oxygen tension $\left(\mathrm{P}_{\mathrm{rv}} \mathrm{O}_{2}\right)$ were measured by oxygen-dependent quenching of phosphorescence lifetimes of the systemically infused albumin-targeted (and therefore circulation-confined) phosphorescent dye Oxyphor G2 [24]. Oxyphor G2 (a two-layer glutamate dendrimer of tetra-(4-carboxy-phenyl) benzoporphyrin) has two excitation peaks $\left(\lambda_{\text {excitation } 1}=440 \mathrm{~nm}, \lambda_{\text {excitation2 }}=632 \mathrm{~nm}\right)$ and one emission peak $\left(\lambda_{\text {emission }}=800 \mathrm{~nm}\right)$. These optical properties allow (near) simultaneous lifetime measurements in microcirculation of the kidney cortex and the outer medulla due to different optical penetration depths of the excitation light [25]. For the measurement of renal venous $\mathrm{PO}_{2}\left(\mathrm{P}_{\mathrm{rv}} \mathrm{O}_{2}\right)$, a mono-wavelength phosphorimeter was used [26]. Oxygen measurements based on phosphorescence lifetime techniques rely on the principle that phosphorescence can be quenched by energy transfer to oxygen, resulting in shortening of the phosphorescence lifetime. A linear relationship between reciprocal phosphorescence lifetime and oxygen tension (given by the Stern-Volmer relation) allows quantitative measurement of $\mathrm{PO}_{2}$ [27].

\section{Renal oxygen delivery and consumption}

Arterial oxygen content $(\mathrm{AOC})$ was calculated by $\left(1.31 \times\right.$ hemoglobin $\left.\times \mathrm{S}_{\mathrm{a}} \mathrm{O}_{2}\right)+(0.003 \times$ $\mathrm{P}_{\mathrm{a}} \mathrm{O}_{2}$ ), where $\mathrm{S}_{\mathrm{a}} \mathrm{O}_{2}$ is the arterial oxygen saturation, and $\mathrm{P}_{\mathrm{a}} \mathrm{O}_{2}$ is the arterial partial pressure of oxygen. Renal venous oxygen content (RVOC) was calculated as $(1.31 \times$ hemoglobin $\times$ $\left.\mathrm{S}_{\mathrm{rv}} \mathrm{O}_{2}\right)+\left(0.003 \times \mathrm{P}_{\mathrm{rv}} \mathrm{O}_{2}\right)$, where $\mathrm{S}_{\mathrm{rv}} \mathrm{O}_{2}$ is the venous oxygen saturation, and $\mathrm{P}_{\mathrm{rv}} \mathrm{O}_{2}$ is the renal vein partial pressure of oxygen (measured using phosphorimetry). Renal oxygen delivery per gram of renal tissue was calculated as $\mathrm{DO}_{2}(\mathrm{~mL} / \mathrm{min} / \mathrm{g})=\mathrm{RBF} \times \mathrm{AOC}$. Renal oxygen consumption per gram of renal tissue was calculated as $\mathrm{VO}_{2}(\mathrm{~mL} / \mathrm{min} / \mathrm{g})=$ $\mathrm{RBF} \times(\mathrm{AOC}-\mathrm{RVOC})$. The renal oxygen extraction ratio was calculated as $\mathrm{O}_{2} \mathrm{ER}(\%)=$ $\mathrm{VO}_{2} / \mathrm{DO}_{2} \times 100$.

\section{Renal function}

For the analysis of urine volume, creatinine concentration, and sodium $\left(\mathrm{Na}^{+}\right)$concentration at the end of the protocol, urine samples from the left ureter were collected for $10 \mathrm{~min}$. Creatinine clearance rate $\left(\mathrm{CL}_{\text {crea }}\right)$ per gram of renal tissue was calculated with standard formula: $\mathrm{CL}_{\text {crea }}(\mathrm{mL} / \mathrm{min} / \mathrm{g})=(U \times V) / P$, where $U$ is the urine creatinine concentration, $V$ is the urine volume per unit time, and $P$ is the plasma creatinine concentration. Renal sodium reabsorption $\left(\mathrm{T}_{\mathrm{Na}+},(\mathrm{mmol} / \mathrm{min})\right)$ was calculated as $\mathrm{T}_{\mathrm{Na}+}=\left(P_{\mathrm{Na}+} \times\right.$ CCR $)-\left(U_{\mathrm{Na}+} \times V\right)$, where $U_{\mathrm{Na}+}$ is the urine sodium concentration, and $P_{\mathrm{Na}+}$ is the plasma sodium concentration. The renal oxygen consumption efficiency for sodium transport $\left(\mathrm{VO}_{2} / \mathrm{T}_{\mathrm{Na}+}\right)$ was assessed as the ratio of the renal $\mathrm{VO}_{2}$ over the total amount of sodium reabsorbed $\left(\mathrm{T}_{\mathrm{Na}+},(\mathrm{mmol} / \mathrm{min})\right)$.

\section{Data analysis}

Statistical analysis was performed using GraphPad Prism version 5.0 for Windows (GraphPad Software Inc., San Diego, CA, USA). Data are presented as median (25\% to $75 \%$ percentiles). The statistical significance of differences between groups was tested using two-way ANOVA with Bonferroni post hoc tests. $P$ values $<0.05$ were considered significant. 


\section{Results}

Table 1 shows the systemic and renal hemodynamic variables: mean arterial pressure (MAP), renal blood flow (RBF), renal vascular resistance (RVR), arterial hemoglobin level $(\mathrm{Hb})$, renal oxygen delivery $\left(\mathrm{DO}_{2}\right)$, renal oxygen consumption $\left(\mathrm{VO}_{2}\right)$, and microvascular oxygen tensions in the renal cortex $\left(\mathrm{C}_{\mu} \mathrm{PO}_{2}\right)$ and medulla $\left(\mathrm{M} \mu \mathrm{PO}_{2}\right)$ at baseline $(\mathrm{BL}) ; 1 \mathrm{~h}$ after the LPS bolus, before the start of fluid resuscitation (LPS); and after $2 \mathrm{~h}$ of fluid resuscitation (FR). Figure 1 shows the renal $\mathrm{DO}_{2}$ and $\mathrm{VO}_{2}$ and $\mathrm{T}_{\mathrm{Na}+}$, renal oxygen handling efficacy $\left(\mathrm{VO}_{2} / \mathrm{T}_{\mathrm{Na}+}\right)$, and creatinine clearance rate at the end of the protocol. No differences in any of these variables between groups were present at baseline.

\section{Systemic and renal hemodynamic variables}

The bolus of LPS $(10 \mathrm{mg} / \mathrm{kg})$ induced a significant drop in MAP and RBF, and a rise in RVR. One hour after LPS administration, all the rats received the same amount of Voluven ${ }^{\circ}$ during the resuscitation protocol, i.e., a bolus of $5 \mathrm{~mL} / \mathrm{kg}$ followed by $5 \mathrm{~mL} / \mathrm{kg} / \mathrm{h}$ for $2 \mathrm{~h}$. Fluid resuscitation could not improve MAP, RBF, and RVR back to baseline level. No additional effects of APC supplementation (10 or $100 \mu \mathrm{g} / \mathrm{kg} / \mathrm{h}$ ) on systemic and renal hemodynamic variables were observed.

\section{Renal oxygenation variables}

In line with $\mathrm{RBF}$, renal $\mathrm{DO}_{2}$ decreased after the LPS bolus in all groups. Fluid resuscitation led to a reduction in the arterial hemoglobin concentration, and therefore, in contrast to RBF, renal $\mathrm{DO}_{2}$ did not improve due to the hemodilution. At the end of the protocol, despite differences in MAP and RBF between the groups, there were no significant differences in $\mathrm{DO}_{2}$. The reduced renal $\mathrm{DO}_{2}$ was also reflected by the reduced microvascular oxygenation in the renal cortex and medulla in all groups. In the APC100 group, the cortical and medullar $\mathrm{PO}_{2}$ was slightly higher than those in other experimental groups; however, this difference was not statistically significant. Even though renal $\mathrm{DO}_{2}$ was decreased after LPS and fluid administration, renal $\mathrm{VO}_{2}$ was maintained throughout the entire protocol. No additional effects of APC supplementation on renal $\mathrm{DO}_{2}$ and $\mathrm{VO}_{2}$ were observed.

\section{Renal function parameters}

At the end of the protocol, creatinine clearance rate and sodium reabsorption had decreased in all endotoxemic groups. Supplementation with APC improved both parameters, albeit not to baseline level. Renal oxygen handling efficacy, as expressed as the amount of oxygen consumed by the kidney per sodium reabsorbed $\left(\mathrm{VO}_{2} / \mathrm{T}_{\mathrm{Na}+}\right)$, was increased fourfold in the endotoxemic group receiving only fluids without APC and less than two-old in the groups receiving APC. Figure 2 shows that renal sodium reabsorption was closely correlated to renal microvascular oxygenation during endotoxemia and resuscitation, and APC supplementation partially protects both renal parameters.

\section{Discussion}

It has been shown in rat models of experimentally induced sepsis that APC has protective effects on the kidney [16-19]. These studies have provided important insights into both the pathophysiology of septic AKI and the potential role of APC in its prevention and/or 
Table 1 Systemic and renal hemodynamic variables in the renal cortex and medulla at three sampling points

\begin{tabular}{|c|c|c|c|c|c|c|c|c|}
\hline$\overline{\mathrm{MAP}(\mathrm{mmHg})}$ & \multicolumn{2}{|c|}{$\mathrm{BL}(t=0 \mathrm{~min})$} & \multicolumn{3}{|c|}{$\operatorname{LPS}(t=60 \mathrm{~min})$} & \multicolumn{3}{|c|}{$\mathrm{FR}(t=180 \mathrm{~min})$} \\
\hline Time control & 99 & $(97-103)$ & 99 & (94-99) & & 90 & $(85-94)$ & \\
\hline$L P S+F R$ & 102 & $(96-109)$ & 77 & $(73-93)$ & $\mathrm{T}$ & 68 & $(44-79)$ & $\mathrm{T}$ \\
\hline APC10 & 100 & $(99-102)$ & 76 & $(69-84)$ & $\mathrm{T}$ & 72 & $(59-78)$ & $\mathrm{T}$ \\
\hline APC100 & 102 & $(102-103)$ & 78 & $(76-92)$ & $\mathrm{T}$ & 81 & $(70-89)$ & $\mathrm{T}$ \\
\hline \multicolumn{9}{|l|}{$\mathrm{RBF}(\mathrm{mL} / \mathrm{min})$} \\
\hline Time control & 6.2 & $(5.8-6.3)$ & 5.9 & $(4.7-6.1)$ & & 5.1 & $(4.7-5.8)$ & \\
\hline$L P S+F R$ & 6.8 & $(6.0-6.8)$ & 3.1 & $(3.1-3.3)$ & $\mathrm{T}$ & 4.6 & $(2.2-5.1)$ & $\mathrm{T}$ \\
\hline APC10 & 6.6 & $(5.0-7.1)$ & 3.2 & $(1.7-4.5)$ & $\mathrm{T}$ & 4.1 & $(2.8-5.1)$ & ${ }^{\top}$ \\
\hline APC100 & 6.0 & $(5.9-6.8)$ & 3.2 & $(2.3-4.2)$ & $\mathrm{T}$ & 4.2 & $(2.8-4.7)$ & $\mathrm{T}$ \\
\hline \multicolumn{9}{|c|}{$\operatorname{RVR}\left(\right.$ dyn s$\left.^{-1} \mathrm{~cm}^{-5}\right)$} \\
\hline Time control & 1,319 & $(1,251-1,373)$ & 1,347 & $(1,301-1,579)$ & & 1,332 & $(1,280-1,558)$ & \\
\hline$L P S+F R$ & 1,276 & $(1,183-1,407)$ & 1,901 & $(1,620-2,673)$ & $\mathrm{T}$ & 1,311 & $(828-2,314)$ & \\
\hline APC10 & 1,267 & $(1,124-1,635)$ & 2,086 & $(1,353-3,222)$ & $\mathrm{T}$ & 1,371 & $(938-2,038)$ & \\
\hline APC100 & 1,331 & $(1,203-1,407)$ & 2,024 & $(1,761-2,743)$ & $\mathrm{T}$ & 1,636 & $(1,383-1,864)$ & \\
\hline \multicolumn{9}{|l|}{$\mathrm{Hb}(\mathrm{g} / \mathrm{dL})$} \\
\hline Time control & 0.19 & $(0.18-0.20)$ & 0.18 & $(0.17-0.20)$ & & 0.18 & $(0.15-0.19)$ & \\
\hline$L P S+F R$ & 0.19 & $(0.17-0.20)$ & 0.17 & $(0.17-0.18)$ & & 0.13 & $(0.12-0.14)$ & ${ }^{\mathrm{T}}$ \\
\hline APC10 & 0.19 & $(0.18-0.20)$ & 0.19 & $(0.17-0.20)$ & & 0.13 & $(0.12-0.14)$ & $\mathrm{T}$ \\
\hline APC100 & 0.19 & $(0.18-0.19)$ & 0.18 & $(0.17-0.19)$ & & 0.13 & $(0.11-0.14)$ & ${ }^{\mathrm{T}}$ \\
\hline \multicolumn{9}{|c|}{$\mathrm{DO}_{2}(\mathrm{~mL} \mathrm{O} / \mathrm{min} / \mathrm{g})$} \\
\hline Time control & 0.90 & $(0.82-0.95)$ & 0.80 & $(0.60-0.93)$ & & 0.69 & $(0.56-0.78)$ & \\
\hline$L P S+F R$ & 0.87 & $(0.77-0.96)$ & 0.39 & $(0.37-0.43)$ & $\mathrm{T}$ & 0.46 & $(0.22-0.48)$ & $\mathrm{T}$ \\
\hline APC10 & 0.89 & $(0.81-0.99)$ & 0.41 & $(0.26-0.63)$ & $\mathrm{T}$ & 0.40 & $(0.25-0.52)$ & $\mathrm{T}$ \\
\hline APC100 & 0.85 & $(0.80-0.97)$ & 0.45 & $(0.28-0.61)$ & $\mathrm{T}$ & 0.37 & $(0.29-0.49)$ & ${ }^{\mathrm{T}}$ \\
\hline \multicolumn{9}{|c|}{$\mathrm{VO}_{2}(\mathrm{~mL} \mathrm{O} / 2 \mathrm{~min} / \mathrm{g})$} \\
\hline Time control & 0.16 & $(0.12-0.20)$ & 0.18 & $(0.08-0.26)$ & & 0.18 & $(0.16-0.19)$ & \\
\hline$L P S+F R$ & 0.13 & $(0.12-0.17)$ & 0.11 & $(0.08-0.15)$ & & 0.17 & $(0.11-0.18)$ & \\
\hline APC10 & 0.18 & $(0.12-0.19)$ & 0.13 & $(0.07-0.16)$ & & 0.14 & $(0.11-0.20)$ & \\
\hline APC100 & 0.17 & $(0.13-0.24)$ & 0.12 & $(0.10-0.17)$ & & 0.16 & $(0.14-0.21)$ & \\
\hline \multicolumn{9}{|l|}{$\mathrm{C}_{\mathrm{PPO}}(\mathrm{mmHg})$} \\
\hline Time control & 86 & $(82-87)$ & 85 & $(78-92)$ & & 71 & $(66-79)$ & \\
\hline$L P S+F R$ & 83 & $(77-87)$ & 69 & $(65-77)$ & $\mathrm{T}$ & 49 & $(43-51)$ & ${ }^{\mathrm{T}}$ \\
\hline APC10 & 82 & $(81-87)$ & 75 & $(65-83)$ & $\mathrm{T}$ & 56 & $(49-59)$ & $\mathrm{T}$ \\
\hline APC100 & 80 & $(75-88)$ & 67 & $(64-75)$ & $\mathrm{T}$ & 68 & $(54-71)$ & \\
\hline \multicolumn{9}{|l|}{$\mathrm{M} \mathrm{PO}_{2}(\mathrm{mmHg})$} \\
\hline Time control & 65 & $(59-66)$ & 62 & $(57-67)$ & & 58 & $(53-60)$ & \\
\hline$L P S+F R$ & 55 & $(51-66)$ & 55 & $(50-57)$ & $\mathrm{T}$ & 40 & $(35-44)$ & ${ }^{\mathrm{T}}$ \\
\hline APC10 & 62 & $(55-64)$ & 53 & $(47-60)$ & $\mathrm{T}$ & 45 & (39-49) & $\mathrm{T}$ \\
\hline APC100 & 59 & $(55-69)$ & 55 & $(49-59)$ & $\mathrm{T}$ & 55 & $(49-58)$ & \\
\hline
\end{tabular}

Data are presented as median ( $25 \%$ to $75 \%$ percentiles). MAP, mean arterial pressure; RBF, renal blood flow; RVR, renal vascular resistance; $\mathrm{Hb}$, arterial hemoglobin level; $\mathrm{DO}_{2}$, renal oxygen delivery; $\mathrm{VO}_{2}$, renal oxygen consumption; $\mathrm{C}_{\mu} \mathrm{PO}_{2}$, microvascular oxygen tension in the renal cortex; microvascular oxygen tension in the medulla $\left(\mathrm{M} \mu \mathrm{PO}_{2}\right) ; \mathrm{BL}$, baseline $(\mathrm{BL})$; LPS, lipopolysaccharide; $\mathrm{FR}$, fluid resuscitation. ${ }^{\top} p<0.05$ vs time control. 


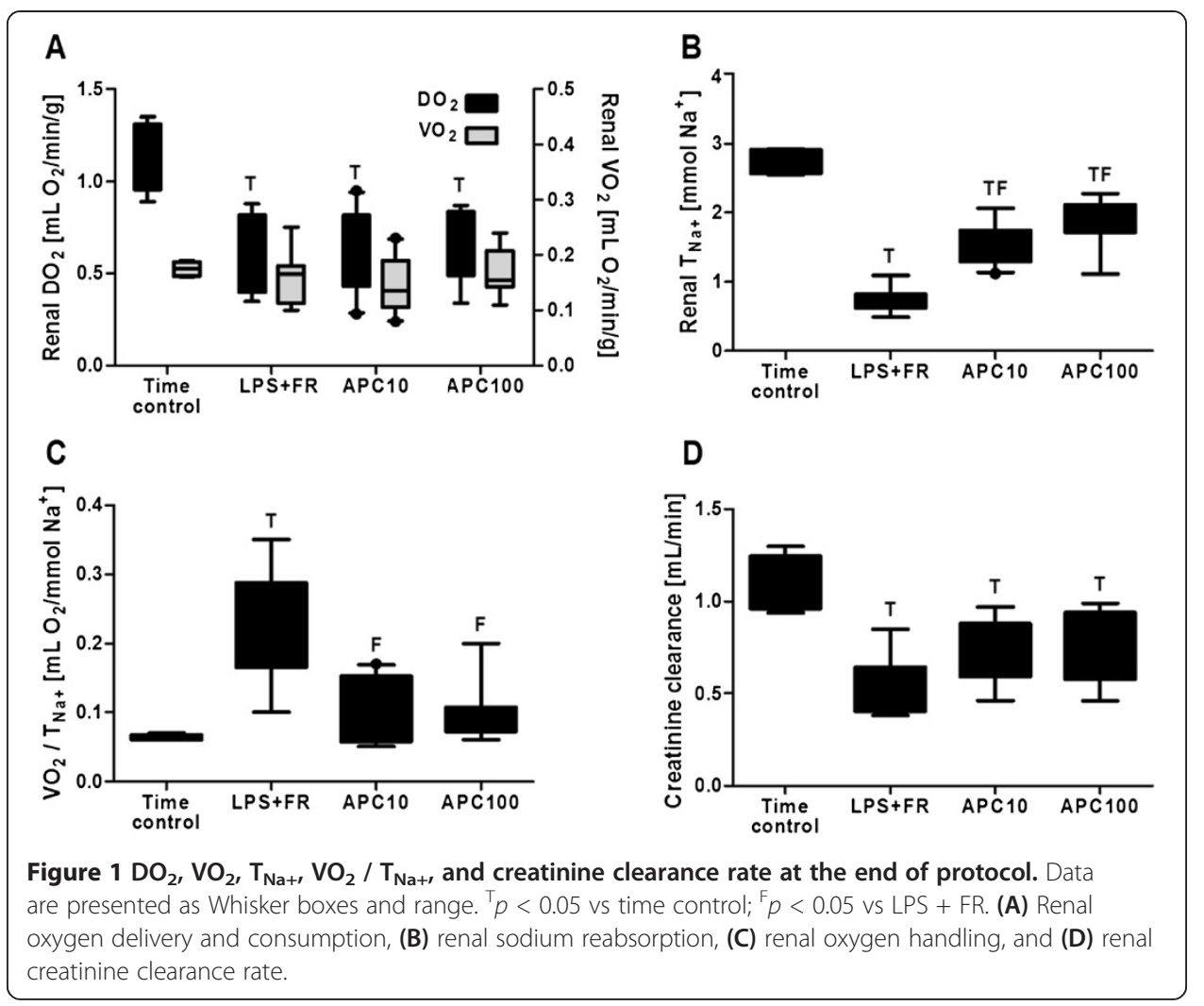

treatment. In the present study, we aimed to test whether continuous recombinant human APC administration would be able to protect renal oxygenation and function during the acute phase of lipopolysaccharide-induced endotoxemia and fluid resuscitation. Although APC has been withdrawn from the market, investigating its effects in studies like this is still very relevant as it might provide more insight into the development of septic AKI.

In our model, endotoxemia and fluid resuscitation led to progressive renal vasoconstriction (increased RVR and decreased RBF) and a decrease in renal $\mathrm{DO}_{2}$ and microvascular oxygenation, a fall in glomerular filtration rate (decreased creatinine clearance), and a fourfold rise in the amount of oxygen consumed by the kidney per sodium reabsorbed $\left(\mathrm{VO}_{2} / \mathrm{T}_{\mathrm{Na}}\right)$. Our main findings regarding the effects of APC were that APC did not have significant effects on the systemic and renal hemodynamic and oxygenation variables or
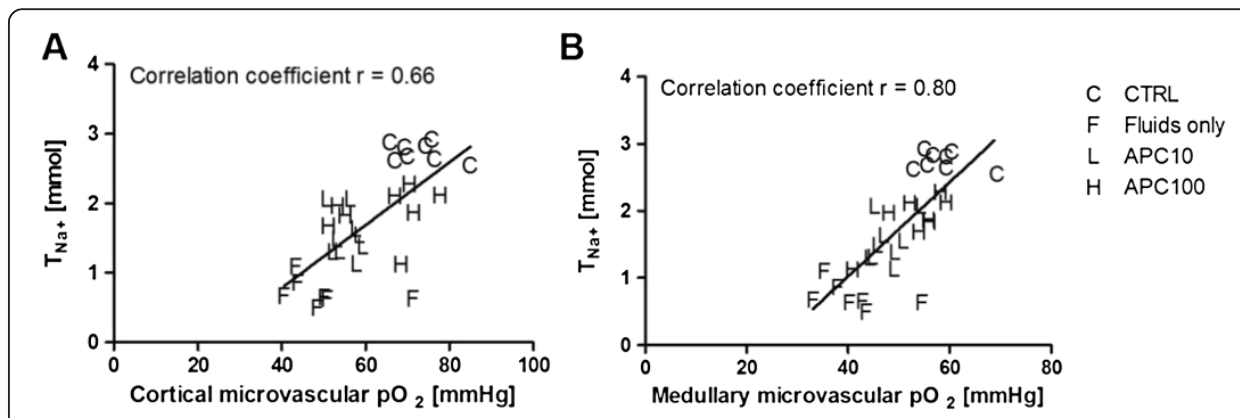

Figure 2 Renal sodium reabsorption $\left(\mathrm{T}_{\mathrm{Na}+}\right)$ versus the microvascular oxygenation. In the renal cortex (A) and medulla (B) at the end of the protocol in all groups. 
creatinine clearance. In the fluid resuscitation group, MAP was slightly lower than those in the other experimental groups, however not significant. Despite lower MAP values, RBF was higher than those in the APC10 and APC100 groups. There were no statistical differences in $\mathrm{DO}_{2}$ between groups at the end of the protocol. Particularly, in the APC100 group, both renal cortical and medullary microvascular oxygenation were better preserved than in fluid resuscitation alone. However, this difference was not statistically significant. In addition, sodium reabsorption and oxygen consumption per sodium reabsorbed $\left(\mathrm{VO}_{2} / \mathrm{T}_{\mathrm{Na}+}\right)$ were preserved in the APC10 and APC100 groups as compared to fluid resuscitation alone. Renal sodium reabsorption was closely correlated to renal microvascular oxygenation during endotoxemia and resuscitation, suggesting a better renal oxygen handling and less renal damage. Nevertheless, there was no assessment of cellular hypoxia or damage to confirm the suggestion above.

Although the mechanisms underlying acute renal failure are not completely defined, in the early stage of sepsis, impairment of the renal microcirculation is believed to be a key complication potentially leading to renal failure [25,28-30]. In addition to an imbalance between physiological vasoactive compounds, it has been suggested that hypoxic microvascular areas might arise in the renal cortex in untreated endotoxemia [5]. These hypoxic areas are considered to reflect shunting of weak microcirculatory units [31,32]. In the present study, $100 \mu \mathrm{g} / \mathrm{kg}$ APC-treated rats had less reduction of microvascular oxygenation than that observed in the other groups. As mentioned above, this was not statistically significant due to small-sized groups. Also, MAP was slightly higher in APC-treated rats, compared to that with fluid resuscitation alone. It might be suggested that the changes in the renal microvascular oxygenation are related to those in systemic blood pressure. However, RBF and DO2 were not influenced by the mild changes in systemic blood pressure.

Furthermore, APC treatment did not affect renal $\mathrm{DO}_{2}$ or $\mathrm{VO}_{2}$. This could also be explained by reduced microvascular shunting in the APC100 group: when blood is shunted from the microcirculation, the remaining microcirculatory blood would deoxygenate more rapidly, while venous oxygenation would be maintained as this is mixed microcirculatory blood and shunted blood from the arterial side. It has been shown that serine protease protein $\mathrm{C}$ plays an important role in controlling thrombosis and inflammation and that it exhibits cytoprotective properties [26]. There is evidence that in septic patients, a reduced plasma level of protein $\mathrm{C}$ is prognostic for clinical outcome [33]. With respect to the protective effects of APC on the kidney during sepsis, especially, the group of Gupta et al. has identified specific mechanisms of action of APC in rat models of experimentally induced septic AKI $[16,19]$. In these studies, rats simultaneously received LPS and 10, 30 , or $100 \mu \mathrm{g} / \mathrm{kg}$ APC. In the present study, the rats first received an LPS bolus, and fluid resuscitation was started $1 \mathrm{~h}$ later with 0,10 , or $100 \mu \mathrm{g} / \mathrm{kg} / \mathrm{h}$ APC. We did not investigate the direct acting mechanisms of APC in our present study but merely focused on the acute effects of APC-supplemented fluid resuscitation in the kidneys of endotoxemic rats. Mimicking the clinical use of APC, at a rate of $24 \mu \mathrm{g} / \mathrm{kg} / \mathrm{h}$ for $96 \mathrm{~h}$ was neither practical nor was our aim in this study.

The increase in $\mathrm{VO}_{2} / \mathrm{T}_{\mathrm{Na}}$ following LPS and fluid resuscitation without APC could either indicate less efficient oxygen use for ATP production for $\mathrm{Na}^{+}$reabsorption or that oxygen is used for other purposes than ATP production such as ROS generation. In a recently published review [34], we described that ischemia/reperfusion injury, also 
arises during hypotensive (septic) shock and resuscitation, is associated with intrarenal microcirculatory dysfunction caused by an imbalance between vasoconstrictors and vasodilators, endothelial damage and endothelium-leukocyte interactions [35-37], oxidative stress [38,39], and oxygen handling [40-42]. Alterations in oxygen transport pathways can result in cellular hypoxia and/or dysoxia [33]. This condition is associated with mitochondrial failure and/or activation of alternative pathways for oxygen consumption $[34,43]$. This could explain the observed rise in $\mathrm{VO}_{2} / \mathrm{T}_{\mathrm{Na}+}$ here.

Another explanation for the observed increase of $\mathrm{VO}_{2} / \mathrm{T}_{\mathrm{Na}+}$ is the back leak phenomenon. Renal $I / R$ injury is shown to cause derangements of the tubule cell cytoskeleton, altered integrity of tight junctions between cells and loss of epithelial polarity, ultimately providing a pathway for back leak of filtrate. These impairments are suggested to cause uncoupling of renal sodium transport and oxygen consumption, leading to inefficient sodium reabsorption. In this view, the above described results of this study might also be explained by prevention of $I / R$-induced renal cell injury in APC-treated rats and protective effects of APC on cellular integrity and tight junction structure [44,45].

There is some evidence that traditional HES solutions can impair renal function and should be used with caution in patients with renal insufficiency [46]. In contrast, the latest generation of HES with low molecular weight and low degree of substitution (such as HES 130/0.4) is suggested to have minimal influence on renal function and coagulation. In 2006, Johannes et al., using phosphorescence lifetime technique, studied the influence of fluid resuscitation and fluid of choice on renal microvascular oxygenation in a similar model of endotoxemia [47]. HES 130/0.4 had least influence on renal $\mathrm{VO}_{2}$ and restored renal function. In this view, we have decided to choose HES 130/0.4 for fluid resuscitation during our study.

We are aware that our study suffers from some limitations. First, no markers of systemic or renal inflammation or coagulation disorders or oxidative stress were measured. Instead, we merely focused on the acute physiological effects of APC-supplemented fluid resuscitation on renal oxygenation, oxygen handling, and function. Second, endotoxemic models may not reflect all the situations encountered in human sepsis and may lack relevance in gram-positive sepsis. However, it is a reproducible model of acute inflammation that involves similar pathways and thus allows us to study the pathophysiology and potential treatment of endotoxemia-induced AKI. Extrapolation of this model to clinical scenarios in terms of treatment strategies should be made with utmost caution. Instead, our study should be regarded as adding to our understanding of the factors contributing to renal microcirculatory failure and potential treatment strategies. Third, the present study only allows assessment of the acute effects of LPS, fluid resuscitation, and APC supplementation in this short-term rat model. APC was infused for $2 \mathrm{~h}$, and the experiments only lasted $3 \mathrm{~h}$ in total which may be insufficient to see any hemodynamic effect. Fourth, the only drug specifically approved for sepsis (recombinant human APC) has been withdrawn from the market. However, investigating its effects in experimental studies is still very relevant as it potentially provides new insights into the development and treatment of septic AKI.

\section{Conclusions}

In conclusion, our data suggest that renal sodium reabsorption is closely correlated to renal microvascular oxygenation during experimentally induced endotoxemia. APC 


\section{supplementation to standard resuscitation protocol partially protected both renal parameters. The specific mechanisms responsible for these protective effects of APC warrant further study.}

\section{Competing interests}

All authors declare that they have no competing interests.

\section{Authors' contributions}

$E A, T J, E G M$, and $C l$ participated in the research design. EA conducted the experiments. EA, TJ, and RB performed data analysis. $E A, T J, R B, A B J G$, and $\mathrm{Cl}$ contributed to the writing of the manuscript. $\mathrm{RB}, \mathrm{KEU}$, and $\mathrm{Cl}$ provided supervision. All authors read and approved the final manuscript.

\section{Acknowledgements}

This study was partially supported by a grant from Eli Lilly and Co. as part of an investigator-initiated investigation. Eli Lilly and Co. was not involved in the design, analysis, or interpretation of the study or in the decision to publish the data.

\section{Author details}

${ }^{1}$ Department of Translational Physiology, Academic Medical Center, University of Amsterdam, Meibergdreef 9, 1105 AZ Amsterdam, The Netherlands. 'Department of Anesthesiology and Intensive Care, St. Antonius Hospital, Nieuwegein, The Netherlands. ${ }^{3}$ Department of Anesthesiology, Erasmus MC University Medical Center, Rotterdam, The Netherlands. ${ }^{4}$ Department of Anesthesiology and Intensive Care Medicine, University Hospital Tübingen, Tübingen, Germany.

${ }^{5}$ Department of Intensive Care, Erasmus MC University Medical Center, Rotterdam 3015 GE, The Netherlands.

Received: 9 October 2013 Accepted: 10 October 2013

Published: 29 October 2013

\section{References}

1. Neveu H, Kleinknecht D, Brivet F, Loirat P, Landais P (1996) Prognostic factors in acute renal failure due to sepsis. Results of a prospective multicentre study. The French Study Group on Acute Renal Failure. Nephrol Dial Transplant 11:293-299

2. Oppert M, Engel C, Brunkhorst FM, Bogatsch H, Reinhart K, Frei U, Eckardt KU, Loeffler M, John S, German Competence Network Sepsis (Sepnet) (2008) Acute renal failure in patients with severe sepsis and septic shock-a significant independent risk factor for mortality: results from the German Prevalence Study. Nephrol Dial Transplant 23:904-909

3. VA/NIH Acute Renal Failure Trial Network, Palevsky PM, Zhang JH, O'Connor TZ, Chertow GM, Crowley ST, Choudhury D, Finkel K, Kellum JA, Paganini E, Schein RM, Smith MW, Swanson KM, Thompson BT, Vijayan A, Watnick S, Star RA, Peduzzi P (2008) Intensity of renal support in critically ill patients with acute kidney injury. N Engl J Med 359:7-20

4. Molitoris BA, Sutton TA (2004) Endothelial injury and dysfunction: role in the extension phase of acute renal failure. Kidney Int 66:496-499

5. Johannes T, Mik EG, Ince C (2009) Non-resuscitated endotoxemia induces microcirculatory hypoxic areas in the renal cortex in the rat. Shock 31:97-103

6. Linas SL, Whittenburg D, Repine JE (1991) Role of neutrophil derived oxidants and elastase in lipopolysaccharide-mediated renal injury. Kidney Int 39:618-623

7. Schrier RW, Wang W (2004) Acute renal failure and sepsis. N Engl J Med 351:159-169

8. Fourrier $F$ (2004) Recombinant human activated protein $C$ in the treatment of severe sepsis: an evidence-based review. Crit Care Med 32:S534-S541

9. Bernard GR (2003) Drotrecogin alfa (activated) (recombinant human activated protein C) for the treatment of severe sepsis. Crit Care Med 31:S85-S93

10. Esmon CT (2001) Protein C anticoagulant pathway and its role in controlling microvascular thrombosis and inflammation. Crit Care Med 29:S48-S51

11. Bernard GR, Vincent JL, Laterre PF, LaRosa SP, Dhainaut JF, Lopez-Rodriguez A, Steingrub JS, Garber GE, Helterbrand JD, Ely EW, Fisher CJ, Jr, Recombinant human protein C Worldwide Evaluation in Severe Sepsis (PROWESS) study group (2001) Efficacy and safety of recombinant human activated protein C for severe sepsis. N Engl J Med 344:699-709

12. Favory R, Lancel S, Marechal X, Tissier S, Neviere R (2006) Cardiovascular protective role for activated protein C during endotoxemia in rats. Int Care Med 32:899-905

13. Grinnell BW, Joyce D (2001) Recombinant human activated protein C: a system modulator of vascular function for treatment of severe sepsis. Crit Care Med 29:S53-S60

14. Hoffmann JN, Vollmar B, Laschke MW, Inthorn D, Fertmann J, Schildberg FW, Menger MD (2004) Microhemodynamic and cellular mechanisms of activated protein C action during endotoxemia. Crit Care Med 32:1011-1017

15. Taylor FB, Jr, Chang A, Esmon CT, D'Angelo A, Vigano-D'Angelo S, Blick KE (1987) Protein C prevents the coagulopathic and lethal effects of Escherichia coli infusion in the baboon. J Clin Invest 79:918-925

16. Gupta A, Rhodes GJ, Berg DT, Gerlitz B, Molitoris BA, Grinnell BW (2007) Activated protein C ameliorates LPS-induced acute kidney injury and downregulates renal INOS and angiotensin 2. Am J Physiol Renal Physiol 293:F245-F254

17. Gupta A, Berg DT, Gerlitz B, Sharma GR, Syed S, Richardson MA, Sandusky G, Heuer JG, Galbreath EJ, Grinnell BW (2007) Role of protein C in renal dysfunction after polymicrobial sepsis. J Am Soc Nephrol 18:860-867

18. Gupta A, Gerlitz B, Richardson MA, Bull C, Berg DT, Syed S, Galbreath EJ, Swanson BA, Jones BE, Grinnell BW (2009) Distinct functions of activated protein C differentially attenuate acute kidney injury. J Am Soc Nephrol 20:267-277 
19. Gupta A, Williams MD, Macias WL, Molitoris BA, Grinnell BW (2009) Activated protein C and acute kidney injury: selective targeting of PAR-1. Curr Drug Targets 10:1212-1226

20. Mizutani A, Okajima K, Uchiba M, Noguchi T (2000) Activated protein C reduces ischemia/reperfusion-induced renal injury in rats by inhibiting leukocyte activation. Blood 95:3781-3787

21. Martí-Carvajal AJ, Solà I, Gluud C, Lathyris D, Cardona AF (2012) Human recombinant protein C for severe sepsis and septic shock in adult and paediatric patients. Cochrane Database Syst Rev 12:12

22. Johannes T, Mik EG, Ince C (2006) Dual-wavelength phosphorimetry for determination of cortical and subcortical microvascular oxygenation in rat kidney. J Appl Physiol 100:1301-1310

23. Mik EG, Johannes T, Ince C (2008) Monitoring of renal venous $\mathrm{PO}_{2}$ and kidney oxygen consumption in rats by a near-infrared phosphorescence lifetime technique. Am J Physiol Renal Physiol 294:F676-F681

24. Dunphy I, Vinogradov SA, Wilson DF (2002) Oxyphor R2 and G2: phosphors for measuring oxygen by oxygen-dependent quenching of phosphorescence. Anal Biochem 310:191-198

25. Klenzak J, Himmelfarb J (2005) Sepsis and the kidney. Crit Care Clin 21:211-222

26. Joyce DE, Gelbert L, Ciaccia A, DeHoff B, Grinnell BW (2001) Gene expression profile of antithrombotic protein C defines new mechanisms modulating inflammation and apoptosis. J Biol Chem 276:11199-11203

27. Bezemer R, Faber DJ, Almac E, Kalkman J, Legrand M, Heger M, Ince C (2010) Evaluation of multi-exponential curve fitting analysis of oxygen-quenched phosphorescence decay traces for recovering microvascular oxygen tension histograms. Med Biol Eng Comput 48:1233-1242

28. Weinberg JR, Boyle P, Thomas K, Murphy K, Tooke JE, Guz A (1991) Capillary blood cell velocity is reduced in fever without hypotension. Int J Microcirc Clin Exp 10:13-19

29. De Backer D, Creteur J, Preiser JC, Dubois MJ, Vincent JL (2002) Microvascular blood flow is altered in patients with sepsis. Am J Respir Crit Care Med 166:98-104

30. Sakr Y, Dubois MJ, De Backer D, Creteur J, Vincent JL (2004) Persistent microcirculatory alterations are associated with organ failure and death in patients with septic shock. Crit Care Med 32:1825-1831

31. Ince C, Sinaasappel M (1999) Microcirculatory oxygenation and shunting in sepsis and shock. Crit Care Med 27:1369-1377

32. Ince C (2005) The microcirculation is the motor of sepsis. Crit Care 9:S13-S19

33. Fisher CJ, Jr, Yan SB (2000) Protein C levels as a prognostic indicator of outcome in sepsis and related diseases. Crit Care Med 28:S49-S56

34. Legrand M, Mik EG, Johannes T, Payen D, Ince C (2008) Renal hypoxia and dysoxia after reperfusion of the ischemic kidney. Mol Med 14:502-516

35. Sutton TA, Mang HE, Campos SB, Sandoval RM, Yoder MC, Molitoris BA (2003) Injury of the renal microvascular endothelium alters barrier function after ischemia. Am J Physiol Renal Physiol 285:F191-F198

36. Yamamoto T, Tada T, Brodsky SV, Tanaka H, Noiri E, Kajiya F, Goligorsky MS (2002) Intravital videomicroscopy of peritubular capillaries in renal ischemia. Am J Physiol Renal Physiol 282:F1150-F1155

37. Hörbelt M, Lee SY, Mang HE, Knipe NL, Sado Y, Kribben A, Sutton TA (2007) Acute and chronic microvascular alterations in a mouse model of ischemic acute kidney injury. Am J Physiol Renal Physiol 293:F688-F695

38. Schnackenberg CG (2002) Physiological and pathophysiological roles of oxygen radicals in the renal microvasculature. Am J Physiol Regul Integr Comp Physiol 282:R335-R342

39. Li C, Jackson RM (2002) Reactive species mechanisms of cellular hypoxia-reoxygenation injury. Am J Physiol Cell Physiol 282:C227-C241

40. Jassem W, Fuggle SV, Rela M, Koo DD, Heaton ND (2002) The role of mitochondria in ischemia/reperfusion injury. Transplantation 73:493-499

41. Pan Y, Mansfield KD, Bertozzi CC, Rudenko V, Chan DA, Giaccia AJ, Simon MC (2007) Multiple factors affecting cellular redox status and energy metabolism modulate hypoxia-inducible factor prolyl hydroxylase activity in vivo and in vitro. Mol Cell Biol 27:912-925

42. Coremans JM, Van Aken M, Naus DC, Van Velthuysen ML, Bruining HA, Puppels GJ (2000) Pretransplantation assessment of renal viability with NADH fluorimetry. Kidney Int 57:671-683

43. Connett RJ, Honig CR, Gayeski TE, Brooks GA (1990) Defining hypoxia: a systems view of $\mathrm{VO}_{2}$, glycolysis, energetics, and intracellular $\mathrm{PO}_{2}$. J Appl Physiol 68:833-842

44. Kwon O, Nelson WJ, Sibley R, Huie P, Scandling JD, Dafoe D, Alfrey E, Myers BD (1998) Backleak, tight junctions, and cell-cell adhesion in postischemic injury to the renal allograft. J Clin Invest 101(10):2054-2064

45. Lewy JE, Windhager EE (1968) Peritubular control of proximal tubular fluid reabsorption in the rat kidney. Am J Physiol 214(5):943-954

46. Wargenau M, Bepperling F, Baron JF (2002) The pharmacokinetics and tolerability of an intravenous infusion of the new hydroxyethyl starch 130/0.4 (6\%, $500 \mathrm{~mL})$ in mild-to-severe renal impairment. Anesth Analg 95(3):544-551

47. Johannes T, Mik EG, Nohé B, Raat NJ, Unertl KE, Ince C (2006) Influence of fluid resuscitation on renal microvascular $\mathrm{PO}_{2}$ in a normotensive rat model of endotoxemia. Crit Care 10(3):R88

doi:10.1186/2197-425X-1-5

Cite this article as: Almac et al:: Activated protein C ameliorates impaired renal microvascular oxygenation and sodium reabsorption in endotoxemic rats. Intensive Care Medicine Experimental 2013 1:5. 